\title{
FILHOS DO ESTADO: SITUAÇÃO DAS CRIANÇAS SOB A TUTELA DO ESTADO EM BELO HORIZONTE
}

\section{CHILDREN OF THE STATE: CHILDREN'S SITUATION UNDER THE STATE OF BELO HORIZONTE}

MATHEUS RAYOL BRAGA

Graduando em Direito, modalidade integral, pela Escola Superior Dom Helder Câmara. Belo Horizonte - MG. E-mail: matheusrayolbraga@gmail.com

CAIO AUGUSTO SOUZA LARA Mestre e Doutor em Direito pela Faculdade de Direito da Universidade Federal de Minas Gerais - UFMG. Professor da Escola Superior Dom Helder Câmara. Pesquisador Associado ao Programa RECAJ-UFMG - Acesso à Justiça e Solução de Conflitos. Secretário de Comunicação do Conselho Nacional de Pesquisa e Pósgraduação em Direito - CONPEDI. Belo Horizonte-MG. E-mail: caiolarabh@yahoo.com.br.

\section{RESUMO}

O tema-problema que pretende-se desenvolver é a situação das crianças e adolescentes sob a tutela do Estado em Belo Horizonte-MG. Pretende-se desvendar a forma como o Estado atua para garantir e zelar pelos direitos das crianças previstos na Constituição da República de 1988, bem como no Estatuto da Criança e do Adolescente. A importância da discussão deste tema passa principalmente pelo fato de que os jovens que se encontram nessa situação já têm o desenvolvimento afetado pela falta da família como aparato social e é papel do Estado provir o necessário para 


\section{Personalidade Acadêmica Homenageada:}

Augustus B. Cochran III (Agnes Scott College)

que eles tenham um desenvolvimento pleno de suas potencialidades. O cumprimento do artigo 7ํㅡㄹ ECA é um desafio por si só quando se trata de crianças e adolescentes sob a tutela do Estado. Com a crise generalizada em que o Estado se encontra, é natural que o tratamento desses menores esteja bem longe do adequado. Neste contexto, é necessário que a sociedade se atente para esta situação para que eles não sejam abandonados. Ao dar mais visibilidade ao tema, aumenta a preocupação da população e, portanto, uma cobrança por parte dela ocorre para que a situação seja devidamente abordada pelos órgãos públicos encarregados e assim garantindo o cumprimento dos direitos estabelecidos no ECA. O presente projeto de pesquisa situa-se na área de Direitos Humanos subárea Direito da Criança e do Adolescente. O problema objeto da investigação científica proposta é: como o Estado atua para garantir direitos concernentes às crianças e adolescentes previstos na Constituição da República e no Estatuto da Criança e do Adolescente até que esta seja realocada em uma família substituta? O trabalho traz como objetivo geral analisar como o Estado atua para garantir os direitos da criança e adolescente que estão sob sua tutela e como elas vivem enquanto aguardam uma família ou mesmo antes de atingirem a maioridade. A pesquisa que se propõe pertence à vertente metodológica jurídicosociológica. No tocante ao tipo de investigação, foi escolhido, na classificação de Witker (1985) e Gustin (2010), o tipo jurídico-projetivo. O raciocínio desenvolvido na pesquisa será predominantemente dedutivo. De acordo com a técnica de análise de conteúdo, afirma-se que trata-se de uma pesquisa teórica o que será possível a partir da análise de conteúdo dos textos doutrinários, normas e demais dados colhidos na pesquisa. Como conclusão parcial da pesquisa tem-se que o estado não consegue suprimir as necessidades das crianças sobre sua tutela e não só suas necessidades para a que eles alcancem resultados e tenham sucesso na vida adulta mas também as necessidades do jovem no seu atual momento de vida para que ele tenha uma vida digna desde sempre como trata Dalmo de Abreu Dallari: "Toda criança nasce com o direito de ser. É um erro muito grave, que ofende o direito de ser, conceber a criança como apenas um projeto de pessoa, como alguma coisa que no futuro poderá adquirir a dignidade de um ser humano. É preciso reconhecer e não esquecer em momento algum, que, pelo simples fato de existir, a criança já é uma pessoa e por essa razão 
Personalidade Acadêmica Homenageada:

Augustus B. Cochran III (Agnes Scott College)

merecedora do respeito que é devido exatamente na mesma medida a todas as pessoas (DALLARI; KORCZACK, 1986, p. 21). Com isso em vista é necessário maior investimento e mudanças no sistema principalmente no que se trata do suporte psicológico a esses jovens para que eles tenham enfim a vida que merecem.

PALAVRAS-CHAVE: Crianças e adolescentes; ressocialização; Função do Estado; atuação do Estado.

\section{REFERÊNCIA}

CUNHA, Carolini; BOARINI, Maria. A infância sob a tutela do Estado: alguns apontamentos. 2010. Disponível em: http://pepsic.bvsalud.org/scielo.php?script=sci_arttext\&pid=S151636872010000100017\&lng=pt\&nrm=iso\&tlng=pt. Acesso em: 12 maio 2019.

GOUDINHO, Hawlison. A função do estado e seu papel na ressocialização do adolescente em conflito com a lei. Disponível em: https://monografias.brasilescola.uol.com.br/direito/a-funcao-estado-seu-papel-naressocializacao-adolescente-conflito-com-a-lei.htm. Acesso em: 12 maio 2019.

GUSTIN, Miracy Barbosa de Sousa; DIAS, Maria Tereza Fonseca. (Re)pensando a pesquisa jurídica: teoria e prática. 3ª . ed. Belo Horizonte: Del Rey, 2010.

LIBERATI, Wilson Donizeti. Comentários ao estatuto da criança e do adolescente. 5‥ ed. São Paulo: Editora Malheiros, 2000.

MULLER, Crisna. Direitos Fundamentais: a proteção integral de crianças e adolescentes no Brasil. [S.I.], 201-. Disponível em: http://www.ambitojuridico.com.br/site/index.php?n_link=revista_artigos_leitura\&artigo_id=9619. Acesso em: 12 maio 2019.

NOGUEIRA, Julio Llanán. Infancias recortadas e instituciones: legalidades al margen. Revisa Jurídica - UNICURITIBA, Curitiba, v.1, n.30, p.32-46, 2013. Disponível em: http://revista.unicuritiba.edu.br/index.php/RevJur/article/view/553 em:21/05/2019

Acesso

SILVA, Moacyr Motta da. VERONESE, Josiane Rose Petry. A tutela jurisdicional dos Direitos da Criança e do Adolescente. São Paulo, Ed LTR, 1998. 
Personalidade Acadêmica Homenageada:

Augustus B. Cochran III (Agnes Scott College)

WITKER, Jorge. Como elaborar uma tesis en derecho: pautas metodológicas y técnicas para el estudiante o investigador del derecho. Madrid: Civitas, 1985. 